\title{
Effects of Eccentric Activation Training of Plantar Flexors for the Patients with Stroke
}

\author{
Dong-Won Kim, PT, PhD' ${ }^{1}$, Ji-Hye Kim, PT, $\mathrm{PhD}^{2}$, Jae-Hyun Kim, PT, PhD ${ }^{* 3}$ \\ ${ }^{1}$ Dept. of Physical Therapy, Bobath Memorial Hospital, Republic of Korea \\ ${ }^{2}$ Dept. of Physical Therapy, Gangdong University, Republic of Korea \\ ${ }^{*}$ Dept. of Physical Therapy, Sinsung Univertsity, Republic of Korea
}

Purpose The aim of this study was to identity the effects of eccentric activation training of plantar flexors on balance and gait in patients with stroke. Methods A total of 30 patients were randomly allocated into two groups: The study group eccentric activation training of plantar flexors $(n=14)$, and the control group conventional training ( $n=16)$. Both groups received equal amount of therapy sessions for 30 minutes a day, 3 times a week for 8 weeks. Results The study group showed significant changes of ankle range of motion in active dorsi flexion $(\mathrm{p}<0.05)$. The study group showed significant changes in the standing balance. There were significant increased in foot pressure $(\mathrm{p}<0.05)$. The study group showed significant changes in velocity, cadence, NP step length, P step length, NP stance time, P stance time compared to the control group $(\mathrm{p}<0.05)$. Conclusion Based on results of this study, the eccentric activation of plantar flexors was effective therapeutic approach in improving ankle range of motion, balance, gait for stroke patients.

Key words Plantar flexors, Eccentric activation, Ankle range of motion, Balance, Gait

Corresponding author Jae-Hyun Kim (anatomy2@naver.com)

Received date 30 Jan 2020

Revised date 12 Feb 2020

Accept date 14 Feb 2020

\section{Introduction}

Contractures, defined as the loss of passive joint range of motion, are a common complication after stroke. ${ }^{1)}$ If the plantar flexors of the ankle joints is severely rigid, it may impair leg advancement during walking and cause problems such as asymmetrical posture, impaired balance, deterioration of walking ability, and loss of elaborate movement control. ${ }^{2)}$ Hemiplegic patients due to a stroke develop severe left and right imbalances and asymmetrical postures due to reduced mobility, which leads to serious problems with balance, such as right reactions and equilibrium reactions. ${ }^{3}$ )

Ankle joints play a role in controlling small shaking in the body, which is also associated with the recovery of balance control. ${ }^{4)}$ Insufficient lengths of the calf muscles, soleus and Achilles tendons and abnormal joint structure of the ankle joint limit the range of flexion of the foot, delay the advancement of the ti- bial bone on the talus bone, and result in a compensatory excessive upset in the ankle joint when walking. 5) During the early stage of the leg support, the plantar flexors serve to control the tibia as well as the foot. As the tibia bone progresses, plantar flexors provide ankle stability and produce motion in the ankle joint. ${ }^{6}$ Stroke patients are unable to control their tibia bones, resulting in shorter steps and decreased walking speed. ${ }^{7)}$ The driving force of the paralyzed leg is believed to indicate morbidity as the propulsion asymmetry between the paralyzed and non-paralyzed legs is highly correlated with the degree of hemiplegia. ${ }^{8)}$ Previous studies have shown that strengthening plantar flexors and dorsi flexors, which are used as a training method for strengthening the ankle muscles of stroke patients, has a positive effect on gait. ${ }^{9)}$ Muscle weakness, loss of balance and gait disturbances in stroke patients lead to the conclusion that strength training is necessary. ${ }^{10)}$ Resistance training with eccentric contraction may be an advantageous way for increasing neuromuscular activation after a stroke out of 
various muscle strength training methods. ${ }^{11)}$ The interest in eccentric activation training is rising because it consumes less energy and gives less burden to the cardiorespiratory system compared to general training. ${ }^{12)}$ The purpose of this study is to investigate the effect of eccentric activation training of plantar flexors on balance and gait in stroke patients.

\section{Materials and Methods}

\section{Study subjects}

The subjects of this study were voluntary participants who had been diagnosed with a stroke for more than six month at a hospital in Seongnam, south of Korea. This study was conducted from July 1 to August 23, 2019. Selection was made through the following selection criteria. Thirty-two stroke patients who met the criteria of this study were randomly divided into a study group and a control group, each consisting of 16, followed by intervention. In order to secure objectivity of treatment intervention, ten physical therapists who had treated brain injury patients working at hospital in Seongnam, Gyeonggi Province, for more than five years were recruited and conducted a study for a total of eight weeks three times a week.

\section{Selection Criteria}

1) Those who have been diagnosed with a stroke and have a disease duration of six months or longer.

2) The patient does not have severe leg sensation loss and orthopedic problems.

3) Those who can walk $10 \mathrm{~m}$ without aid.

4) Those who have a score of 24 or higher on K-MMSE.

5) Anyone who can walk for 6 minutes independently without any abnormality in blood pressure, pulse, and breathing.

6) Those who understand and consent to the participation agreement of this study.

\section{Study design}

In this study, two groups of pre- and post-test designs were used as single-blind measures. The study group was randomly assigned into two groups: an eccentric activation training group of plantar flexors and a convetional training group. A total of 32 randomly selected patients were assigned to study and control groups, and a preliminary evaluation was performed. For both groups, three times a week for 30 minutes

Table 1. General characteristics of the subjects(n=30)

\begin{tabular}{cccc} 
& Study $(\mathrm{n}=14)$ & Control(n=16) & $\chi^{2} / \mathrm{t}$ \\
Gender(M/F,\%) & $7 / 7$ & $6 / 10$ & 0.29 \\
Age(years) & $(50 / 50)$ & $(37.5 / 62.5)$ & 0.74 \\
Height(cm) & $51.93 \pm 3.27$ & $48.63 \pm 3.97$ & 0.46 \\
Body weight(kg) & $165.18 \pm 2.38$ & $163.62 \pm 2.31$ & 0.07 \\
Type of stroke & $66.92 \pm 3.07$ & $63.75 \pm 2.70$ & 0.57 \\
(hemorrhage/infarction,\%) & $10 / 4$ & $(56.25 / 43.75)$ & $8 / 7$ \\
Paretic side(Rt/Lt,\%) & $(71.43 / 28.57)$ & $(50 / 50)$ & 0.32 \\
Duration(month) & $6 / 8$ & $16.13 \pm 3.54$ & -0.02 \\
K-MBI(scores) & $13.43 \pm 2.72$ & $67.24 \pm 3.14$ & 0.10 \\
K-MMSE(scores) & $67.34 \pm 3.22$ & $26.21 \pm 2.37$ & 0.64 \\
\hline
\end{tabular}

mean \pm standard deviation.

Study group : eccentric training of plantar flexors.

Control group : conventional training. 
in each session, the study group conducted eccentric activation training of plantar flexors, and the control group underwent conventional training. The study period was eight weeks, and the evaluation items were ankle range of motion, balance ability measurement, and gait test. Two participants were dropped out of the study group, with one due to deteriorating health and the other due to an insufficient number of attendance in training sessions.

\section{Outcome Measures}

1) Electronic Digital Goniometer

The measuring instrument used in the clinical field has a total length of $20 \mathrm{~cm}$, an adjustable angle of $0.05^{\circ}$, a measuring range of $0-360^{\circ}$, with an accuracy range of $\pm 0.3^{\circ}$. To measure the range of motion of the ankle joint using a goniometer, the hip and knee joints were extension and laid down on the mat. The axis of the goniometer was placed in the lateral malleolus, with the fixed arm parallel to the line connecting the fibular head on the outside of the calf, and the moving arm parallel to the line connected to the metatarsal bone of the fifth toe. This makes the angle between the inflection of the ankle joint and the sole of the foot $0^{\circ}$. Then it is measured by the method of AAOS (1965), which calculates the angle to the scale at which the moving arm moves(Figure 1). ${ }^{17)}$

2) MTD system

MTD (balance version 4.0) consists of a monitor and computer used to measure balance using two scaffolds to measure the subject's balance when standing, and software to analyze the balance. The subject places the feet on the two force plates in the position marked with bare feet. The MTD system's measurement items include the balance of the two feet in standing position, the left and right weight shift, the balance ability of the two feet upon standing from the sitting position, and the left and right weight shift. Zhai examined the correlation between the MDT system, Berg balance test, and Fugl-Meyer balance test in healthy adults. ${ }^{18)}$ As a result, the MDT system showed a high correlation and was reported to be a reliable instrument for measuring balance(Figure 2). ${ }^{19)}$

\section{3) GAITRite system}

In order to measure the spatio-temporal variables related to the stance phase and swing phase during the gait of stroke patients, the GAITRite ${ }^{\mathrm{TM}}$ system (CIR System Inc., USA), which has been validated and reliable for stroke patients, was used. GAITRite consists of a $61 \mathrm{~cm}$-wide and $366 \mathrm{~cm}$-long walkway, and is equipped with pressure-sensitive sensors that can accurately measure the spatio-temporal gait characteristics of those walking on it by computer analysis. In this study, we used the velocity, cadence, the stance time, the swing time, which are temporal gait variables, in addition to the step length and the stride length, which are spatial walking variables, obtained through GAITRite as the variables for symmetry of

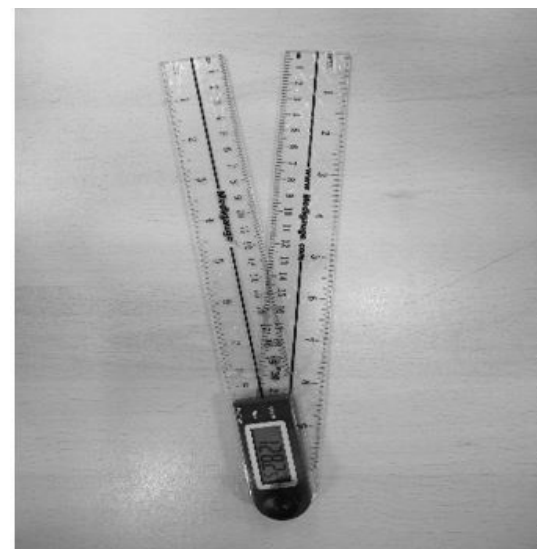

Figure 1. Goniometer

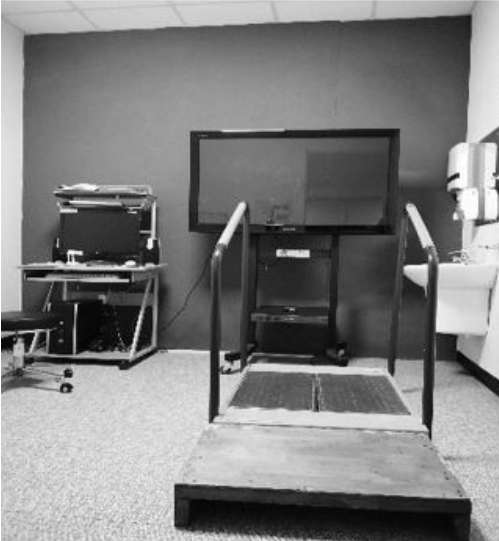

Figure 2. MTD system

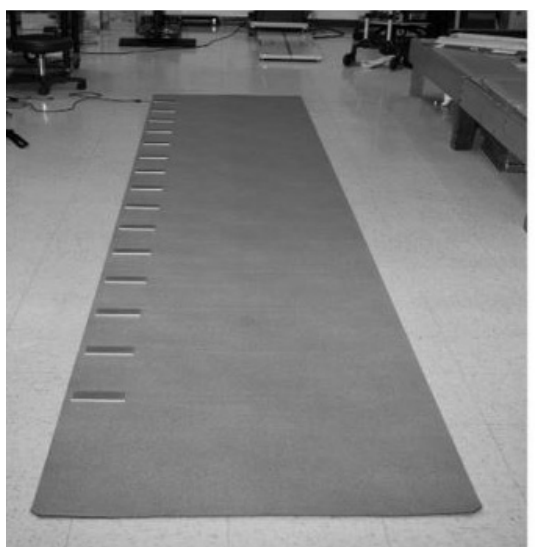

Figure 3. GAITRite 
gait(Figure 3). ${ }^{20)}$

\section{Therapeutic interventions}

(1) Prone position : The ankle joint maintains dorsi flexion position, contact the soleus muscle in an array shape, and multiful angle, multiful velocity repeats eccentric activation training of the soleus. (2) Sit to stand, stand to sit : Paretic side foot is placed in dorsi flexion then Eccentric activation training of plantar flexors through Sit to stand or stand to sit. (3) Standing position : Apply at a slope so that the muscle length can be longer than flat. Both can be applied at the same time, or only paretic side if necessary. contact with the shape of the muscles of the soleus so that it can be further stimulated when the heel comes down (longer muscle length). (4) stance phase training : With the paretic leg in front of you, you should be in a standing position with a light support of your body in the bending position of your foot. At this time, restricting the knee movement can strengthen the eccentric stimulation applied to the foot. In particular, when the soleus muscle becomes shorter and weaker, such as the medial gastrocnemius muscle, it becomes difficult to control the antagonism of the tibialis anterior muscle and the movement. The ability to generate muscle strength involves structural, mechanical, and neurological factors.

\section{Statistical analysis}

All statistics in this study were calculated using SPSS Statistics Windows version 21.0 to calculate the mean and standard deviation. The Shapiro-Wilk test was performed for normality test for each measurement item. The general characteristics of the subjects were expressed using descriptive statistics, and the Chi-square test and independent t-test were performed to determine the differences among the groups. Non-parametric tests were used to compare the ankle range of motion, balance ability, and pre- and post measures of gait analysis between the two groups (between groups: the Mann-Whitney U test within groups: the Wilcoxon rank test). All statistical significance levels $(\alpha)$ of the data were 0.05 .

\section{Results}

\section{Change in range of motion of ankle joint}

The range of motion dorsi flexion before training in the study group increased $1.25^{\circ}$ from $7.56^{\circ}$ to $8.81^{\circ}$
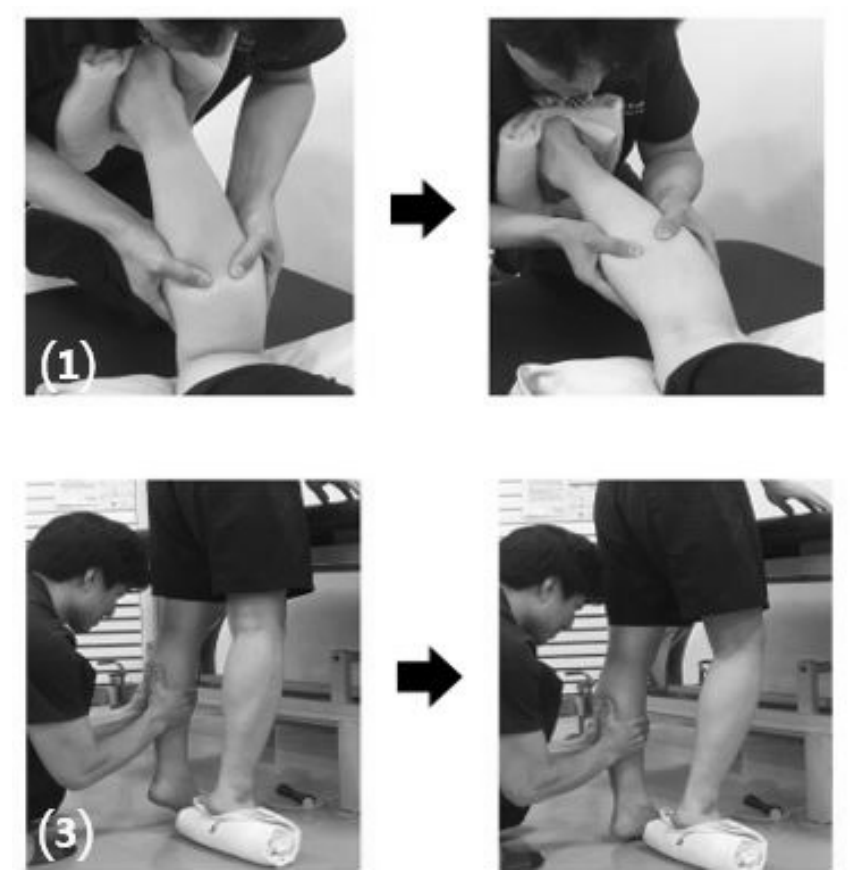
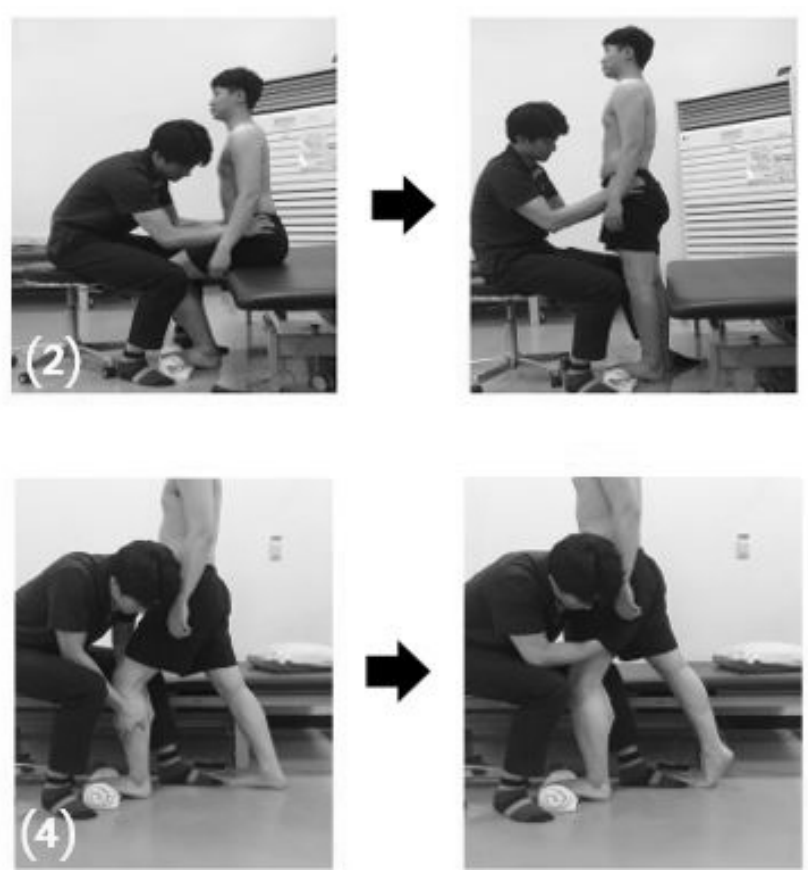
after intervention, and the change before and after intervention was statistically significant $(\mathrm{p}<0.01)$.

\section{Change in standing balance}

In foot pressure, the study group had an average change of $9.71 \%$ from $39.00 \%$ at the toe before intervention and at $48.71 \%$ at the heel after intervention, with statistically significant changes before and after intervention $(\mathrm{p}<0.01)$.

\section{Change in gait}

The change in velocity was $37.50 \mathrm{~m} / \mathrm{s}$ before intervention and $32.81 \mathrm{~m} / \mathrm{s}$ after intervention, which was statistically significant before and after intervention ( $p$ $<0.05)$. The Cadence in the study group was 73.98 steps / min before intervention and 70.50 steps / min after intervention, which was statistically significant ( $\mathrm{p}$ $<0.05)$. The step length of nonparetic steps from 28.19 $\mathrm{cm}$ to $32.20 \mathrm{~cm}$. The step length change in the paretic step was $30.95 \mathrm{~cm}$ before intervention and $34.14 \mathrm{~cm}$ after intervention $(\mathrm{p}<0.05)$. The non-paretic stance time change of the study group was 1.14 sec before intervention and $1.31 \mathrm{sec}$ after intervention, which was statistically significant before and after intervention. The change in the paretic stance time of the study group was $1.01 \mathrm{sec}$ before intervention and $1.18 \mathrm{sec}$ after intervention, which was statistically significant $(\mathrm{p}<0.05)$.

Table 3. Comparison within and between the three groups $(n=27)$

\begin{tabular}{|c|c|c|c|c|c|c|c|c|}
\hline \multirow[b]{2}{*}{$\left({ }^{\circ}\right)$} & \multicolumn{3}{|c|}{$\begin{array}{l}\text { Study group } \\
\qquad(n=14]\end{array}$} & \multicolumn{3}{|c|}{$\begin{array}{l}\text { Control group } \\
\qquad(n=16]\end{array}$} & \multirow[b]{2}{*}{ z } & \multirow[b]{2}{*}{$\mathrm{p}$} \\
\hline & pre & post & $\begin{array}{l}\text { Change } \\
\text { (post-pre) }\end{array}$ & pre & post & $\begin{array}{l}\text { Change } \\
\text { (post-pre) }\end{array}$ & & \\
\hline $\mathrm{ADF}$ & $7.56 \pm 8.21$ & $8.81 \pm 7.47$ & $1.25 \pm 1.06^{* * *}$ & $9.67 \pm 8.10$ & $10.08 \pm 7.80$ & $0.41 \pm 0.82^{*}$ & -2.05 & $.041^{*}$ \\
\hline $\mathrm{APF}$ & $26.21 \pm 7.81$ & $29.21 \pm 6.48$ & $3.10 \pm 4.22^{*}$ & $23.13 \pm 6.10$ & $25.03 \pm 5.62$ & $1.91 \pm 1.70^{* * *}$ & -0.04 & .966 \\
\hline PDF & $11.18 \pm 7.94$ & $15.46 \pm 6.52$ & $4.29 \pm 4.91^{* *}$ & $14.75 \pm 6.80$ & $15.89 \pm 6.64$ & $1.14 \pm 1.35^{*}$ & -1.71 & .088 \\
\hline PPF & $32.32 \pm 9.13$ & $36.92 \pm 9.47$ & $4.60 \pm 5.65^{\circ}$ & $29.68 \pm 9.00$ & $32.95 \pm 11.90$ & $3.27 \pm 30.01^{* * *}$ & -0.28 & .782 \\
\hline
\end{tabular}

Note. Values are mean \pm standard deviation, ${ }^{*} p<0.05{ }^{* *} p<0.01{ }^{* * *} p<0.001$

ADF: Active dorsi flexion, APF: Active plantar flexion, PDF: Passive dorsi flexion, PPF: Passive plantar flexion.

$p$ : Mann-Whitney $U$ test.

Study group : eccentric training of plantar flexors.

Control group : conventional training.

Table 3. Comparison of Standing Balance for each group. $(n=30)$

\begin{tabular}{|c|c|c|c|c|c|c|c|c|}
\hline \multirow[b]{2}{*}{$(\%)$} & \multicolumn{3}{|c|}{$\begin{array}{l}\text { Study group } \\
\text { (n=14) }\end{array}$} & \multicolumn{3}{|c|}{$\begin{array}{l}\text { Control group } \\
\qquad(n=16)\end{array}$} & \multirow[b]{2}{*}{$z$} & \multirow[b]{2}{*}{$p$} \\
\hline & pre & post & $\begin{array}{l}\text { Change } \\
\text { (post-pre) }\end{array}$ & pre & post & $\begin{array}{l}\text { Change } \\
\text { (post-pre) }\end{array}$ & & \\
\hline Symmetric standing & $1.58 \pm 4.53$ & $4.64 \pm 4.36$ & $3.06 \pm 5.20$ & $1.31 \pm 4.50$ & $2.05 \pm 8.14$ & $0.74 \pm 6.81$ & -1.58 & .115 \\
\hline Max paretic WB & $55.57 \pm 19.67$ & $57.57 \pm 23.18$ & $4.00 \pm 7.39^{*}$ & $48.00 \pm 25.35$ & $46.53 \pm 30.68$ & $1.47 \pm 11.29$ & -1.23 & .220 \\
\hline Foot pressure & $39.00 \pm 6.98$ & $48.71 \pm 9.26$ & $9.71 \pm 9.01^{* * *}$ & $43.88 \pm 10.76$ & $45.06 \pm 11.60$ & $3.87 \pm 6.70^{*}$ & -2.06 & $.040^{*}$ \\
\hline
\end{tabular}

Note. Values are mean \pm standard deviation, ${ }^{*} p<0.05^{* *} p<0.01^{* * *} p<0.001$

$p$ : Mann-Whitney $U$ test.

Study group : eccentric training of plantar flexors.

Control group : conventional training. 
Table 4. Comparison of Gait (GAITRite) for each group. ( $n=30$ )

\begin{tabular}{|c|c|c|c|c|c|c|c|c|}
\hline & \multirow[b]{2}{*}{ pre } & \multicolumn{2}{|l|}{$\begin{array}{l}\text { Study group } \\
\qquad(n=14]\end{array}$} & \multicolumn{3}{|c|}{$\begin{array}{l}\text { Control group } \\
\qquad(n=16)\end{array}$} & \multirow[b]{2}{*}{ z } & \multirow[b]{2}{*}{$\mathrm{p}$} \\
\hline & & post & $\begin{array}{l}\text { Change } \\
\text { (post-pre) }\end{array}$ & pre & post & $\begin{array}{l}\text { Change } \\
\text { (post-pre) }\end{array}$ & & \\
\hline $\operatorname{Velocity}(\mathrm{m} / \mathrm{s})$ & $37.50 \pm 14.30$ & $32.81 \pm 15.60$ & $-4.69 \pm 10.07^{*}$ & $36.02 \pm 8.97$ & $34.81 \pm 8.56$ & $-1.20 \pm 5.10$ & -2.40 & $.016^{*}$ \\
\hline Cadence(steps/min) & $73.98 \pm 16.91$ & $70.50 \pm 17.15$ & $-3.48 \pm 5.63^{*}$ & $68.68 \pm 17.19$ & $68.47 \pm 17.96$ & $-0.21 \pm 2.77$ & -1.97 & $.049^{*}$ \\
\hline NP step length $(\mathrm{cm})$ & $28.19 \pm 7.12$ & $32.20 \pm 7.95$ & $4.01 \pm 6.51$ & $28.39 \pm 7.43$ & $28.56 \pm 7.58$ & $0.16 \pm 4.94$ & -2.10 & $.036^{*}$ \\
\hline P step length $(\mathrm{cm})$ & $30.95 \pm 8.19$ & $34.14 \pm 9.35$ & $3.18 \pm 6.39^{*}$ & $34.78 \pm 10.90$ & $32.20 \pm 9.37$ & $-2.58 \pm 7.12$ & -2.31 & $.021^{*}$ \\
\hline NP stance time $(\mathrm{sec})$ & $1.14 \pm 0.33$ & $1.31 \pm 0.51$ & $0.17 \pm 0.26^{* *}$ & $1.35 \pm 0.80$ & $1.41 \pm 0.53$ & $0.06 \pm 0.38$ & -2.34 & $.020^{*}$ \\
\hline P stance time $(\mathrm{sec})$ & $1.01 \pm 0.26$ & $1.18 \pm 0.46$ & $0.17 \pm 0.27$ & $1.24 \pm 0.73$ & $1.26 \pm 0.48$ & $0.02 \pm 0.35$ & -2.16 & $.031^{*}$ \\
\hline
\end{tabular}

Note. Values are mean \pm standard deviation, ${ }^{*} p<0.05{ }^{* *} p<0.01{ }^{* * *} p<0.001$

$\mathrm{p}$ : Mann-Whitney $U$ test. $\mathrm{P}$ : Paretic side, NP : Non paretic side.

Study group : eccentric training of plantar flexors.

Control group : conventional training.

\section{Discussion}

The purpose of this study is to investigate the effect of eccentric activation training of plantar flexors on ankle joint ROM, balance and gait in patients with stroke. The research method was clinical randomized study, which was conducted with study group and control group. Treatment intervention was an eccentric activation training of plantar flexors, which was conducted for the purpose of functional carry over effect of progressive muscle activation by activating plantar flexors. Both the study group and the control group were treated for 8 weeks and the following results were obtained. The results on the range of motion of the ankle joint showed a significant change in the active dorsi flexion of stroke patients. The results on balance showed that the foot pressure shifted backward. Among the spatio-temporal variables of gait, there was a statistically significant change in velocity, cadence, paretic side step length, non-paretic side step length, paretic side stance time, non- paretic side stance time. As a result, eccentric activation training of plantar flexors showed improvement in active dorsi flexion of stroke patients. Foot pressure was also an increase in weight bearing to the paretic side heel in balance. In gait, velocity, cadence, paretic step length, non-paretic step length, paretic stance time, non- paretic stance time increased. Activation of the primary motor cortex and the pre-motor cortex occur more strongly, especially in eccentric contractions ${ }^{13)}$. Activation of the prefrontal cortex was also observed before and during eccentric contraction ${ }^{14)}$. There is also a study that the stiffness of the plantar flexors is one of the most important factors for temporal and spatial gait asymmetry ${ }^{15)}$. The other studies, however, report different results and are analyzed with the exception of other impairment factors, such as the strength and range of motion. Therefore, the eccentric activation training of the plantar flexors suggested in this study can be said to be effective in restoring the range of motion of ankle, balance and gait patients with stroke.

In the future, more participants will be needed to generalize the results of the study, and more detailed analysis of factors affecting the range of motion of the ankle joint and the factors influencing them will be needed. A reasonable assessment tool is needed.

\section{Funding information and Acknowledgement}

This paper was supported by the research grant of the Bobath Memorial Hospital in 2019

\section{References}

1. Kwah LK, Harvey LA, Diong JH, et al. Half of the adults who present to hospital with stroke develop at least one contracture within six months: An observational study. 
Journal of Physiotherapy. 2012;58(1):41-7.

2. Caillet F, Mertens P, Rabaséda S, et al. Three dimensional gait analysis and controlling spastic foot on stroke patients. In: Annales de readaptation et de medecine physique: revue scientifique de la Societe francaise de reeducation fonctionnelle de readaptation et de medecine physique. 2003;119-31.

3. Ikai T, Kamikubo T, Takehara I, et al. Dynamic postural control in patients with hemiparesis. American journal of physical medicine \& rehabilitation. 2003;82(6):463-9.

4. Runge C, Shupert C, Horak F, et al. Ankle and hip postural strategies defined by joint torques. Gait \& posture. 1999;10(2):161-70.

5. Sahrmann S. Movement system syndrome of the foot and ankle. Movement system impairment syndromes of the extremities, cervical and thoracic spines $1^{\mathrm{a}}$ ed St Lois: Missouri: Mosby Elsevier. 2011;439-80.

6. Perry J, Burnfield J. Gait analysis: Normal and pathological function. 2nd. Thorofare, NJ: Slack Incorporated. 2010.

7. Lauzière $\mathrm{S}$, Mieville $\mathrm{C}$, Betschart $\mathrm{M}$, et al. A more symmetrical gait after split-belt treadmill walking increases the effort in paretic plantar flexors in people post-stroke. Journal of rehabilitation medicine. 2016;48(7):576-82.

8. Bowden MG, Balasubramanian CK, Neptune RR, et al. Anterior-posterior ground reaction forces as a measure of paretic leg contribution in hemiparetic walking. Stroke. 2006;37(3):872-6.

9. Ng SS, Hui-Chan CW. Contribution of ankle dorsiflexor strength to walking endurance in people with spastic hemiplegia after stroke. Archives of physical medicine and rehabilitation. 2012;93(6):1046-51.

10. Snow LM, Low WC, Thompson LV. Skeletal muscle plasticity after hemorrhagic stroke in rats: Influence of spontaneous physical activity. American journal of physical medicine \& rehabilitation. 2012;91(11):965-76.
11. Roig M, MacIntyre DL, Eng JJ, et al. Preservation of eccentric strength in older adults: Evidence, mechanisms and implications for training and rehabilitation. Experimental gerontology. 2010;45(6):400-9.

12. Laroche D, Joussain C, Espagnac C, et al. Is it possible to individualize intensity of eccentric cycling exercise from perceived exertion on concentric test?. Archives of physical medicine and rehabilitation. 2013;94(8):1621-7.

13. Hedlund $M$, Lindström $B$, Sojka $P$, et al. Is better preservation of eccentric strength after stroke due to altered prefrontal function?. Neurocase. 2016;22(2): 229-42.

14. Fang Y, Siemionow V, Sahgal V, et al. Distinct brain activation patterns for human maximal voluntary eccentric and concentric muscle actions. Brain research. 2004;1023(2):200-12.

15. Hsu AL, Tang PF, Jan MH. Analysis of impairments influencing gait velocity and asymmetry of hemiplegic patients after mild to moderate stroke. Archives of physical medicine and rehabilitation. 2003;84(8):1185-93.

16. Raine $S$. The bobath concept: Developments and current theoretical underpinning. Bobath Concept. 2009:1.

17. Hong WS, Kim GW. Reliability of measurement devices for measuring the ankle joint motion. The Journal of Korean Academy of Orthopedic Manual Physical Therapy. 2009;15(1):1-8.

18. Zhai H, Wang Y, Wang Y, et al. Validity and sensitivity of mtd-balance systems in the assessment of balance function. Shenzhen J Integrated Traditional Chinese and Western Med. 2005;2(002).

19. Kim YG, Kang SH. Effects of virtual reality-based exercise on balance, gait, and falls efficacy in patients with parkinson's disease: A pilot study. Journal of the Korean Society of Integrative Medicine. 2016;4(2):1-11.

20. Kim JH. Relationship between gait symmetry and functional balance, walking performance in subjects with stroke. The Journal of Korean Physical Therapy. 2014;26(1):1-8. 
